\title{
Histidine and tyrosine phosphorylation in pea mitochondria: evidence for protein phosphorylation in respiratory redox signalling
}

\author{
Gunilla Håkansson*, John F. Allen \\ Plant Cell Biology, Lund University, Box 7007, S-220 07 Lund, Sweden
}

Received 11 August 1995

\begin{abstract}
A $37 \mathrm{kDa}$ protein in pea mitochondria was found to contain phosphorylated residues. Phosphorylation was acid-labile but stable in alkali solution, a unique property of phosphorylation on histidine, indicating that a signal transduction pathway with homology to bacterial two-component systems might exist in plant mitochondria. We also describe the first example of tyrosine phosphorylation in plant organelles and the first indication of protein phosphorylation as part of a redox signalling mechanism in mitochondria. Labelling of three proteins (28, 27 and $12 \mathrm{kDa})$ was found to be dependent on the redox state of the reaction medium. Their phospho-groups were resistant to alkali as well as acid treatment and labelling was inhibited by the tyrosine kinase inhibitor genistein.
\end{abstract}

Key words: Redox signalling; Tyrosine phosphorylation; Histidine phosphorylation; Mitochondrion;

Two-component system

\section{Introduction}

Protein phosphorylation regulates a variety of cellular processes and is known to be involved in signal transduction and regulation of enzyme activity in both eukaryotes and prokaryotes [1]. Although the complete picture of interactions between the kinases, phosphatases, substrates and effectors has not been obtained, some general patterns have emerged. In eukaryotes, signal transduction involving phosphorylation is generally initiated at cell surface receptors with tyrosine kinase activity. The signal is then transferred through the cell in a cascade of threonine/serine and tyrosine phosphorylation events. In many cases these events lead to altered gene expression. A typical bacterial signal transduction pathway has two components: a sensor and a response regulator [2]. The sensor, a histidine kinase membrane protein, becomes autophosphorylated on a conserved histidine upon activation. The environmental signal is then communicated to the soluble regulator protein, a transcription factor, with an aspartate phosphorylation site.

Protein kinase activity has also been detected in the chloroplasts (reviewed in [3]) and mitochondria [4-8] of eukaryotic cells, although compared with cytosolic pathways, much less is known about organellar kinases, phosphatases, their substrates and activating signals.

So far, two key enzymes in mammalian mitochondria have been shown to be regulated by phosphorylation. The $\alpha$ subunits of the matrix complexes pyruvate dehydrogenase $(\mathrm{PDH})$ and

*Corresponding author. Fax: (46) (46) $10-4009$ or (46) (46) 10-3684. E-mail: gunilla.hakansson(a) placebio.lu.se branched chain $\alpha$-ketoacid dehydrogenase (BCKDH) are both phosphorylated at serine residues [5,6] and the genes for their specific matrix located kinases have been cloned $[9,10]$. Both kinases were shown to belong to a new group of eukaryotic kinases, lacking motifs usually found in Ser/Thr-protein kinases, but containing motifs associated with prokaryotic histidine kinases.

Besides PDH and BCKDH more than 10 substrates for protein kinases have been detected in mammalian mitochondria, half of which show cAMP-dependent phosphorylation, implying that they phosphorylate proteins on serine or threonine residues $[8,11]$. The majority of these proteins are associated with the inner mitochondrial membrane and three are phosphorylated by a membrane-bound kinase. In yeast, cAMP-dependent protein kinase activity has been observed in association with inner mitochondrial membranes [4]. In plant mitochondria, more than 20 substrates for protein phosphorylation have been detected $[7,12,13]$.

In chloroplasts, phosphorylation of a range of substrates associated with the thylakoid membrane is regulated by the activity of the photosynthetic electron transport chain [14]. Redox titrations showed that most of the substrates are phosphorylated under reducing conditions, that is at high photosynthetic activity. It has further been suggested that the redox potential of the energy-generating membranes in both chloroplasts and mitochondria works as a general signal, which regulates a variety of processes in the organelles, including gene expression [15-17]. In support of this hypothesis, it was recently shown that mitochondria and chloroplasts isolated from pea, alter their protein synthesis in response to changes in redox potential [18]. Redox regulation of gene expression is known to occur for nuclear gene expression in both animals [19] and plant systems [20,21] as well as for bacterial genes [22]. By analogy with other systems, redox transduction in chloroplasts and mitochondria is likely to include phosphorylation events, possibly involving components with homology to bacterial type two component regulatory systems [15-17]. In order to detect possible components involved in mitochondrial redox signalling, we have analyzed protein phosphorylation in isolated pea mitochondria under different redox conditions.

\section{Materials and methods}

\subsection{Isolation of mitochondria}

Garden peas (Pisum sativum L.) were grown under normal greenhouse conditions $\left(20^{\circ} \mathrm{C}\right.$ with a $12 \mathrm{~h}$ day) and mitochondria were isolated from 14-day-old leaves as described earlier $[23,24]$.

\subsection{Protein phosphorylation}

Equal volumes $(5 \mu \mathrm{l})$ of a concentrated mitochondrial suspension were preincubated for $10 \mathrm{~min}$ at $25^{\circ} \mathrm{C}$ in a final volume of $50 \mu \mathrm{l}$ assay mixture [25] complemented with redox agents $(20 \mathrm{mM})$, as indicated 
1a Fig. 1. Labelling of proteins was initiated by addition of $10 \mu \mathrm{Ci}$ $\left[\gamma_{-}{ }^{32} \mathrm{P}\right]$ ATP $(3000 \mathrm{Ci} / \mathrm{mmol})$. The reaction proceeded for $5 \mathrm{~min}$ at $25^{\circ} \mathrm{C}$ and mitochondria was pelleted by a $1 \mathrm{~min}$ spin at $11,600 \times \mathrm{g}$. Each mitochondrial pellet was resuspended in $30 \mu$ electrophoresis buffer (2\% SDS, $10 \%$ glycerol, $1 \%$ dithiothreitol, $10 \mu \mathrm{g} / \mathrm{ml}$ Bromophenol blue, (2.5 mM Tris- $\mathrm{HCl}, \mathrm{pH} 6.8$ ).

In some experiments mitochondrial membranes were separated from natrix prior to electrophoresis. The mitochondrial pellet obtained after ncubation with $\left[\gamma_{-}{ }^{32} \mathrm{P}\right]$ ATP was resuspended by repeated pipetting in $0 \mu 1$ of destilled water and mitochondrial membranes were collected y centifugation at $11,600 \times \mathrm{g}$. The membrane pellet was resuspended $\mathrm{n} 30 \mu \mathrm{l}$ electrophoresis buffer, and $30 \mu \mathrm{l}$ of $3 \times$ electrophoresis buffer vas added to the supernatant containing the matrix fraction.

Phosphorylation was also performed in the presence $100 \mu \mathrm{M}$ of the yrosine kinase inhibitor genistein (4',5,7-trihydroxyisoflavone) obained from Sigma [26]. Isolated mitochondria were either preincubated or $10 \mathrm{~min}$ in the assay mixture supplemented with genistein or the nhibitor was added together with the $\left[\gamma^{32} \mathrm{P}\right]$ ATP.

2.3. Electrophoresis and autoradiography

$50 \%$ of each sample was loaded in each lane of a $12-20 \%$ gradient SDS gel and mitochondrial proteins were separated at $410^{\circ} \mathrm{C}$ and 10 mA constant current. Gels were Coomassie stained, destained and dried it $60^{\circ} \mathrm{C}$ before exposure to Amersham Hyperfilm-MP.
2.4. Acid or alkaline treatment of membrane bound phosphorylated proteins

After phosphorylation and electrophoresis as described above, the proteins were blotted onto a nylon membrane (Hybond-PVDF, Amersham). The membrane was cut into four pieces which were treated for $60 \mathrm{~min}$ in either $0.5 \mathrm{M} \mathrm{HCl}, 0.5 \mathrm{M}$ Tris- $\mathrm{HCl}(\mathrm{pH} 8.8)$ or $0.5 \mathrm{M} \mathrm{NaOH}$, at $65^{\circ} \mathrm{C}$ in a rotating incubator [27]. After treatment the membranes were exposed Amersham Hyperfilm-MP and then stained with Coomassie.

\section{Results}

10-15 labelled proteins were detected when mitochondrial phosphoproteins, obtained as a result of incubating isolated pea mitochondria with $\left[\gamma-{ }^{32} \mathrm{P}\right] \mathrm{ATP}$, were separated in a SDS-gel (Fig. 1a). The most heavily labelled bands represent proteins of 41,28 and $27 \mathrm{kDa}$. Six other proteins of 94, 70,60, 46, 37 and $12 \mathrm{kDa}$ are a also labelled, though less heavily. A number of weakly labelled bands can also be seen. Based on the size of the protein, the degree of labelling and the inhibition by pyruvate (Fig. 4, lane 2), the $41 \mathrm{kDa}$ protein can be assigned as
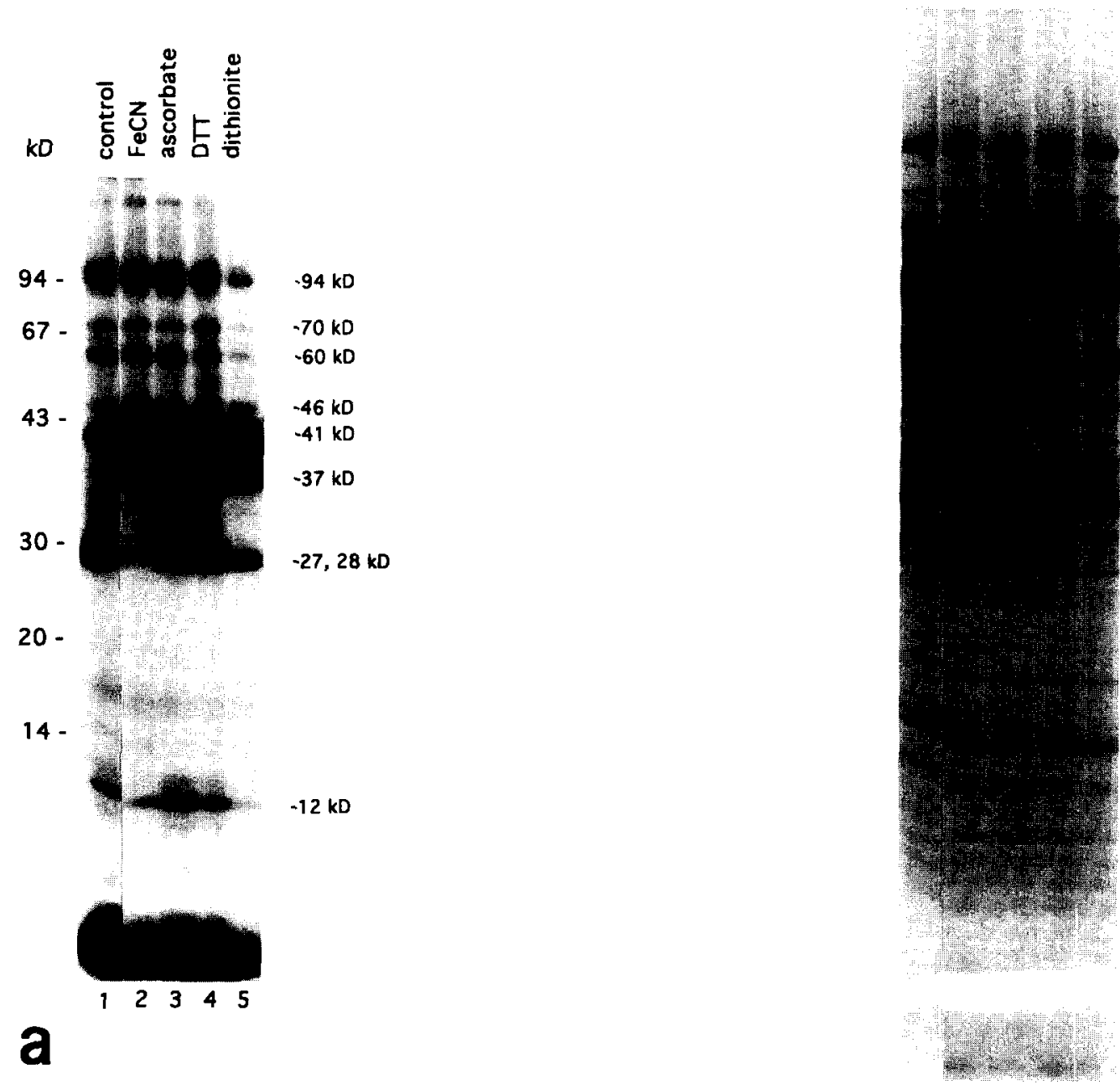

$\begin{array}{lllll}1 & 2 & 3 & 4 & 5\end{array}$

Fig. 1. Redox effect on protein phosphorylation in pea mitochondria. (a) Autoradiograph showing $\left[\gamma-{ }^{32} \mathrm{P}\right]$-labelled proteins. Sizes of molecular weight markers are indicated on the left and sizes of phosphoproteins on the right. (b) Coomassie staining of the same gel. In both panels: Lane $1=$ control; lane $2=$ potassium ferricyanide; lane $3=$ ascorbic acid; lane $4=$ dithiothreitol; lane $5=$ sodium dithionite. 


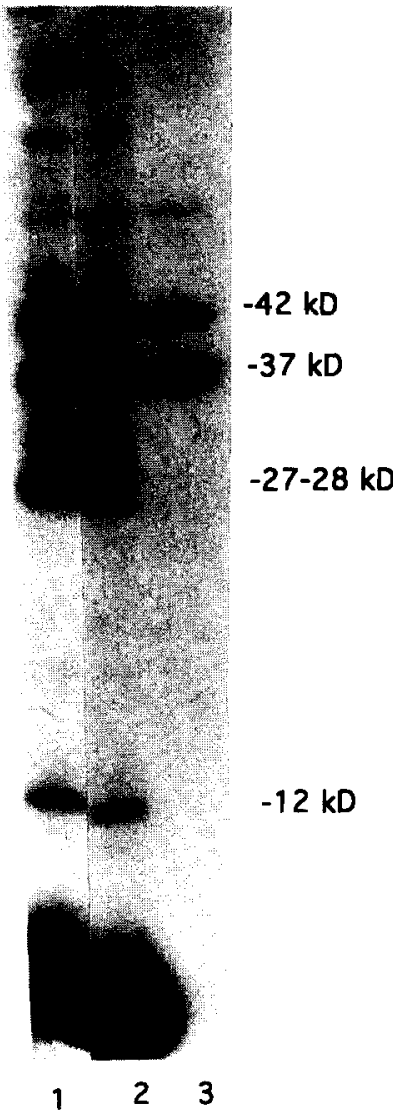

Fig. 2. Fractionation of mitochondrial proteins. Lane $1=$ intact mitchondria; lane 2 = membrane fraction; lane $3=$ soluble fraction.

the $\alpha$ subunit of PDH [5], while the $46 \mathrm{kDa}$ protein might represent the phosphorylated subunit of BCKDH $[6,11]$.

Two of the more heavily labelled proteins ( 27 and $28 \mathrm{kDa})$ and one of the less labelled proteins $(12 \mathrm{kDa})$ show specific changes in phosphorylation under different redox conditions (Fig. 1a), although the Coomassie stained gel shows no differences in intensity of the corresponding bands (Fig. 1b). The 28, 27 and $12 \mathrm{kDa}$ proteins are most heavily labelled (Fig. la) after incubation with ascorbic acid (lane 3) or dithiothreitol (lane 4), which cause mildly reducing conditions. In contrast, the stronger reductant sodium dithionite (lane 5) causes a reduction in the labelling. The lowest labelling, however, is seen after incubation with the oxidizing agent potassium ferricyanide (lane 2). A small difference in the response to the reducing and oxidizing agents can be seen between the 27 and $28 \mathrm{kDa}$ proteins. After incubation with potassium ferricyanide, ascorbic acid or dithiothreitol (lanes 2-4) the band representing the 28 $\mathrm{kDa}$ protein is more intense than the $27 \mathrm{kDa}$ band. However, after treatment with sodium dithionite (lane 5) both proteins are equally labelled.

Fig. 2 shows the effect of lysing the mitochondria in water and separating the membrane from the matrix fraction before electrophoresis. All three redox regulated phosphoproteins (28, 27 and $12 \mathrm{kDa}$ ) are found in the membrane fraction (lane 2), while the main component of the matrix fraction represents the alpha subunit of PDH, together with the $37 \mathrm{kDa}$ protein (lane 3 ), which is more heavily labelled in this experiment than in that of Fig. 1.

Fig. 3 shows that the three redox regulated phosphoproteins
$(28,27$ and $12 \mathrm{kDa})$ all have phoshoryl groups which are stable under both acid (lane 1) and alkali (lane 3) conditions, indicating tyrosine as the phosphorylated residue [28]. In contrast, the $\alpha$ subunit of PDH is labile when treated with alkali (lane 3), but stable under acid conditions (lane 1). This result is consistent with the conclusion that PDH is phosphorylated at serine residues [5,28]. In addition, Fig. 3 shows that the $37 \mathrm{kDa}$ protein is acid-labile, but alkali-stable, a unique property of phosphorylation on histidine [27]. No differences were seen in the protein banding patterns when membranes were stained with Coomassie, after the various treatments (data not shown).

All three redox regulated proteins $(28,27$ and $12 \mathrm{kDa})$ in this investigation are clearly inhibited by the tyrosine kinase inhibitor genistein (Fig. 4, lanes 3 and 4). The effect of inhibition was enhanced when the mitochondrial sample was preincubated with the inhibitor (lane 4). In addition, genistein seems to cause an increase in labelling of the $41 \mathrm{kDa}$ PDH-subunit and the 37 $\mathrm{kDa}$ protein, especially after preincubation with the inhibitor (lane 4).

\section{Discussion}

We have identified three proteins $(28,27$ and $12 \mathrm{kDa})$ whose phosphorylation is influenced by redox conditions. In agreement with the hypothesis on redox regulation of gene expression in chloroplast and mitochondria [15], these phosphoproteins are candidates for components of a redox signal transduc-

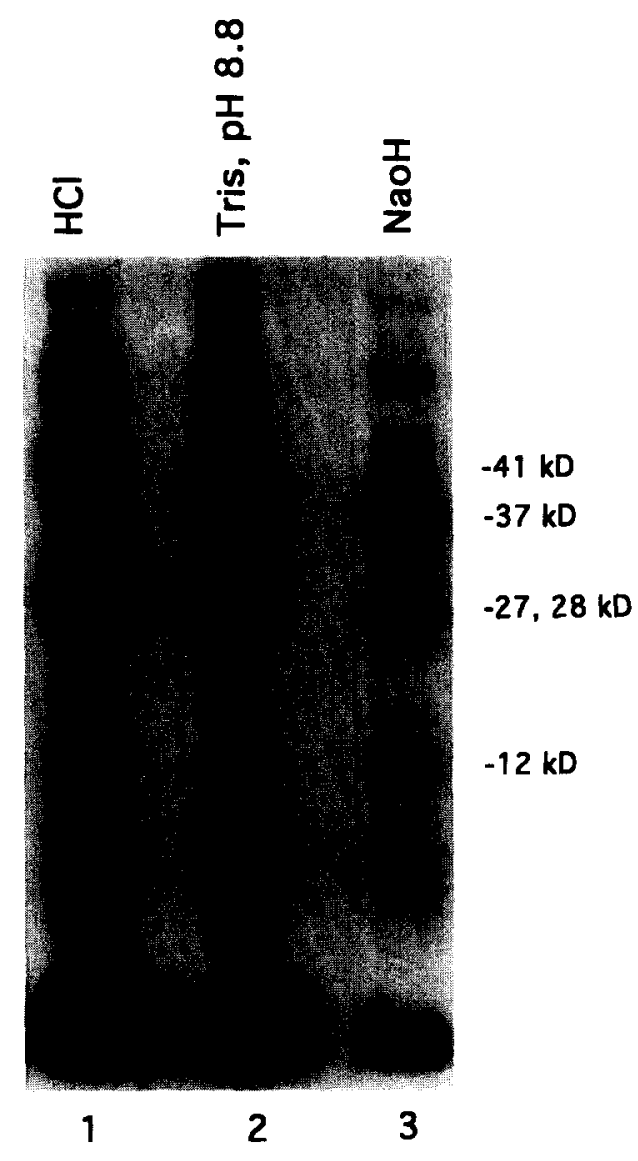

Fig. 3. Acid and alkali treatment of phosphorylated mitochondrial proteins bound to a nylon membrane. 


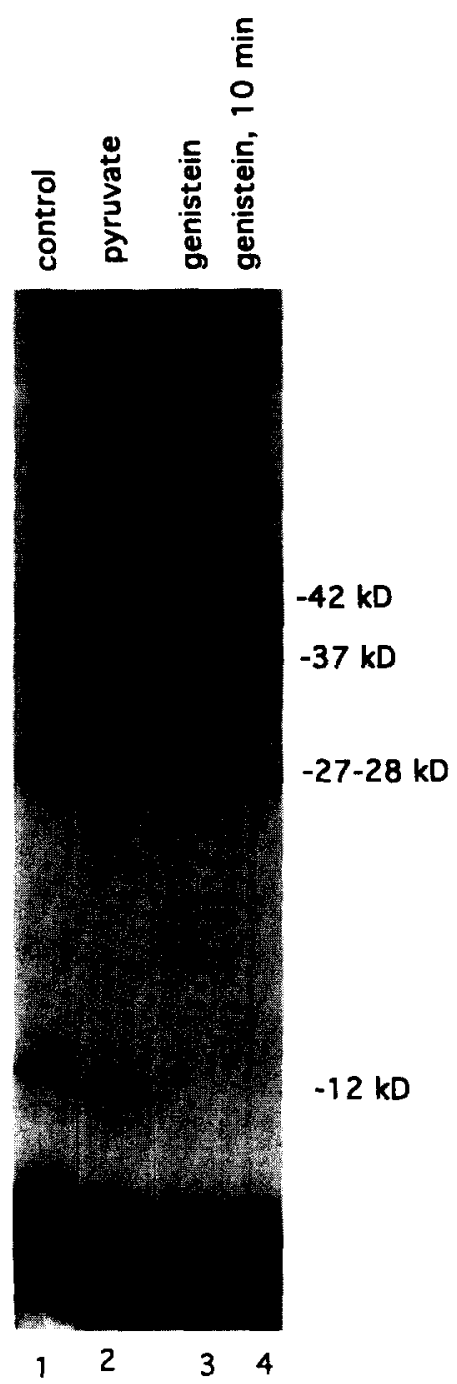

Fig. 4. Effect of genistein on protein phosphorylation. Lane $1=$ control, lane $2=20 \mathrm{mM}$ pyruvate was included in the reaction medium; lane $3=$ genistein added together with the $\left[\gamma^{32}\right.$ P $]$ ATP; lane $4=10 \mathrm{~min}$ preincubation with genistein before addition of $\left[\gamma_{-}{ }^{32}\right.$ P]ATP.

tion pathway in pea mitochondria. In this context, it is intriguing to note that the same conditions (oxidizing conditions caused by potassium ferricyanide or extremely reducing conditions caused by sodium dithionite) that resulted in a decrease in phosphorylation of the 28,27 and $12 \mathrm{kDa}$ proteins in this study, was earlier shown to decrease protein synthesis in isolated pea mitochondria [18].

The fact that the phospho-groups of the redox regulated proteins are stable under both acid and alkali conditions suggests that they are phosphorylated on tyrosine residues [28]. Phosphotyrosine can show higher alkali stability depending on the amino acid environment. However, the lack of labelling of the 28,27 and $12 \mathrm{kDa}$ proteins in the presence of the tyrosine kinase inhibitor genistein, favours the the interpretation that these proteins are phosphorylated on tyrosine residues. Although genistein has been reported also to inhibit some histidine kinases [29], the acid stability of the phospho-groups of the 28,27 and $12 \mathrm{kDa}$ proteins excludes the possibility that they are phosphorylated on histidine [28].

To our knowledge, this is the first report of tyrosine phoshorylation in plant organelles. In eukaryotic signal transduction pathways tyrosine phosphoproteins are typically found in the beginning of the signal pathway as membrane receptor kinases. Since the tyrosine phosphoproteins detected in this study were found to be membrane associated, it is possible that they represent mitochondrial receptor tyrosine kinases which are initial components in a redox signalling pathway in these organelles. Tyrosine phosphorylation has been shown to be involved in redox signal transduction in human T-cells, possibly with the phosphatase as a key regulatory component [30]. Earlier reports show that all known protein-tyrosine phosphatases contain a redox sensitive cysteine in their catalytic domain [31].

So far, tyrosine kinase receptors have been found only in eukaryotic systems, and mitochondria are believed to have a prokaryotic origin. However, regulation of gene expression in response to changes in osmolarity in yeast, which combines bacterial type two-component systems with an eukaryotic-type MAP kinase cascade, shows that there is no strict boundary between prokaryotic and eukaryotic signal transduction pathways [32]. In addition, tyrosine kinase activity has been reported in bacteria [33] and mitochondrial tyrosine kinase activity has been described in undifferentiated fibroblasts and tumours in mammalian systems, where a tyrosine protein kinase activity is associated with the outer mitochondrial membrane $[34,35]$.

Besides showing tyrosine phosphorylation in plant organelles for the first time, this is also the first report of histidine phosphorylation detected in the eukaryotic organelles. Although sequence analysis reveals homology between the animal mitochondrial serine kinases that phosphorylate PDH and BCKDC subunits and histidine phosphoproteins of bacterial two-component regulatory systems $[9,10]$, no biochemical evidence for histidine phosphorylation in eukaryotic organelles has so far been presented [36]. One reason why acid-labile phosphogroups are often overlooked is that most laboratory routines include acid treatment of phosphorylated proteins, such as TCA-precipitation and stains with acetic acid. The fact that the $37 \mathrm{kDa}$ protein was seen as a highly labelled protein in some gels, while it appeared much fainter in others, could probably be referred to differences in staining procedures. Acid treatment of membranes with blotted proteins clearly confirmed the acid lability of the phospho group of the $37 \mathrm{kDa}$ protein.

The discovery of the $37 \mathrm{kDa}$ histidine phosphoproteins in mitochondria of peas in this investigation supports the hypothesis of bacterial type two-component systems in regulation of organelle gene expression [15]. Unlike the 28,27 and $12 \mathrm{kDa}$ tyrosine phosphoproteins, the $37 \mathrm{kDa}$ histidine phosphoprotein does not show redox-dependent phosphorylation under the conditions used in this investigation. Thus, while the 28,27 and $12 \mathrm{kDa}$ proteins may be regarded as candidates for components involved in redox regulation of mitochondrial gene expression [18], the $37 \mathrm{kDa}$ histidine phosphoprotein is most likely part of a different signal transduction system. Both the PDH-kinase and the BCKDH-kinase contain the conserved histidine phosphorylation site of histidine kinases of bacterial two-component systems. The molecular sizes estimated from SDS-gels for these proteins are 48 and $44 \mathrm{kDa}$ respectively. Although it cannot be excluded that the $37 \mathrm{kDa}$ phosphoprotein represents a plant homologue of the serine-kinases from animal mitochondria, the difference in size makes it less likely. 
The effect of the tyrosine kinase inhibitor genistein on the $41 \mathrm{kDa}$ PDH-subunit in this study suggests that typically eukaryotic regulatory phosphorylation cascades are present in the pea mitochondria. Labelling of the PDH-subunit, which is known to be phosphorylated on serine residues [5], was enhanced by treatment with genistein, suggesting that a PDHphosphatase is activated by phosphorylation on a tyrosine residue. The identities of the phosphoproteins described here are currently under investigation.

Acknowledgements: We thank the Swedish Natural Science Research Council (J.F.A.) and Agriculture and Forestry Research Council (G.H.) for support. This study was also financed partly by grants from the Crafoord Foundation. We further thank Andé Struglics and Paul Davies for valuable discussions.

\section{References}

[1] McEntyre, J. (ed.) (1994) Trends Biochem. Sci. 19, 439-518.

[2] Parkinson, J.S. and Kofoid, E.C. (1992) Annu. Rev. Genet. 26 , $71-112$.

[3] Allen, J.F. (1992) Biochim. Biophys. Acta 1098, 275-335.

[4] Müller, G. and Bandlow, W. (1987) Yeast 3, 161-174.

[5] Reed, L.J. and Yeaman, S.J. (1987) Enzymes 18, 77-95.

[6] Randle, P.J., Patson, P.A. and Espinal, J. (1987) Enzymes 18, 97-121.

[7] Sommarin, M., Petit, P.X. and Møller, I.M. (1990) Biochim. Biophys. Acta 1052, 195-203.

[8] Technikova-Dobrova, Z., Sardanelli, A.M. and Papa, S. (1993) FEBS Lett. 322, 51-55.

[9] Popov, K.M., Zhao, Y., Shimomura, Y., Kuntz, M.J. and Harris, R.A. (1992) J. Biol. Chem. 267, 13127-13130.

[10] Popov, K.M., Kedishvili, N.Y., Zhao, Y., Shimomura, Y., Crabb, D.W. and Harris, R.A. (1993) J. Biol. Chem. 268, 2660226606.

[11] Technikova-Dobrova, Z., Sardanelli, A.M., Stanca, M.R. and Papa, S. (1994) FEBS Lett. 350, 187-191.

[12] Pical, C., Rémy, R., Sommarin, M., Møller, I.M. and Petit, P.X. (1992) in: Molecular, Biochemical and Physiological Aspects of Plant respiration (Lambers, H. and van der Plas, L.H.W. eds.) pp. 393-398, SPB Academic Publishing, The Hague.

[13] Pical, C., Fredlund, K.M., Petit, P.X., Sommarin, M., Møller, I.M (1993) FEBS Lett. 336, 347-351.
[14] Silverstein, T., Cheng, L., Allen, J.F. (1993) Biochim. Biophys. Acta $1183,215-220$.

[15] Allen. J.F. (1993a) J. Theor. Biol. 165, 609-631

[16] Allen, J. F. (1993b) Photosynth. Res. 36, 95-102

[17] Allen, J. F. (1993c) FEBS Lett. 332, 203-207.

[18] Allen, C.A., Håkansson, G. and Allen, J.F. (1995) Redox Report. I, 119-123.

[19] Meyer, M., Pahl, H.L. and Baeuerle, P.A. (1994) Chem. Biol. Interact. 91, 91-100.

[20] Babiychuk, E., Kushnir, S., Van Montagu, M. and Inzé, D. (1994) Proc. Natl. Acad. Sci. USA 91, 3299-3303.

[21] Allen, J.F., Alexciev, K. and Håkansson, G. (1995) Curr. Biol. 5, 869-872.

[22] Iuchi, S. and Lin, E.C.C. (1993) Mol. Microbiol. 9, 9-15.

[23] Boutry, M., Faber, A-M., Charbonnier, M. and Briquet, M. (1984) Plant Mol. Biol. 3, 445-452.

[24] Håkansson, G., van der Mark, F., Bonnett, H.T. and Glimelius, K. (1988) Theor. Appl. Genet. 76, 431-437.

[25] Petit, P.X., Sommarin, M., Pical, C. and Møller, M. (1990) Physiol. Plant. 80, 493-499.

[26] Akiyama, T., Ishida, J., Nakagawa, S., Ogawara, H., Watanabe, S., Itoh, N., Shibuya, M. and Fukami, Y. (1987) J. Biol. Chem. $262,5592-5595$.

[27] Oda, K. and Hasunuma, K. (1994) FEBS Lett. 345, 162-166.

[28] Duclos, B., Marcandier, S. and Cozzone, A.J. (1991) Methods Enzym. 201, 10-21.

[29] Huang, J., Nars, M., Kim, Y. and Matthews, H.R. (1992) J. Biol. Chem. 22, 15511-15515.

[30] Staal, F.J.T., Anderson, M.T., Staal, G.E.J., Herzenberg, L.A., Gitler, C. and Herzenberg, L.A. (1994) Proc. Natl. Acad. Sci. USA 91, 3619-3622.

[31] Fischer, E.H., Charbonneau, H. and Tonks, N.K. (1991) Science $253,401-406$

[32] Maeda, T., Wurgler-Murphy, S.M. and Saito, H. (1994) Nature $369,242-245$

[33] Chiang, T.M., Reizer, J. and Beachey, E.H. (1989) J. Biol. Chem. 264, 2957-2962.

[34] Piedimonte, G., Silvotti, L., Chamaret, S., Borghetti, A.F. and Montagnier, L. (1986) J. Cell Biochem. 32, 113-124.

[35] Piedimonte, G., Chamaret, S., Dauguet, C., Borghetti, A. and Montagnier, L. (1988) J. Cell Biochem. 36, 91-102.

[36] Swanson, R.V., Alex, L.A. and Simon, M.I. (1994) Trends Biochem. Sci. $19,485-490$. 